\title{
A Construção/Apropriação da Escrita nas Salas de Aula da Escola Fundamental e NAS SALAS DE BATE-PAPO NA INTERNET
}

(The Construction/Apropriation of Writing in the Classroom of the "Fundamental" School and in the Internet Chat)

\author{
Sérgio Roberto Costa \\ (UFJF/UNINCOR/Três Corações)
}

\begin{abstract}
RESUMO: Na escola, a criança usa um código abreviado, sincopado, em sua escrita inicial, para construir seu discurso, porque ainda não tem domínio do sistema de escritura; também, na internet, os adolescentes usam, nos chats informais, abreviações, síncopes, alongamentos, caixa alta - semelhantes à forma escrita escolar inicial. A partir dessas observações, este artigo descreve e analisa os fenômenos apontados acima, tentando explicar as possiveis semelhanças e diferenças dos dados coletados em circunstâncias e espaços enunciativos diversos, o que poderia contribuir com a compreensão dos processos cognitivos de apropriação e produção da escrita por crianças e adolescentes, destacandose as possiveis similaridades e divergências desses fenômenos e processos.
\end{abstract}

PALAVRAS-CHAVE: escrita; escola; chat; internet.

ABSTRACT: At school, children build their initial written discourse by using an abbreviated, syncopated code because they do not master the written system yet; on the internet, in their informal chats, teenagers' use of abbreviations, syncopes, expansions, upper case also remind us of the initial school writing form. This article describes and analyses the phenomena mentioned above by trying to explain the possible similarities and differences in the data collected in varied circumstances and enunciatory environments in an attempt to contribute to the understanding of the cognitive processes of appropriation and production of writing by children and adolescents. Special emphasis will be given to the similarities and differences of those phenomena and processes. KEY-WORDS: writing; school; chat; internet. 


\section{Introdução}

As crianças, quando vão para a escola, devem se apropriar sistematicamente do código alfabético de sua língua materna para escrever. Trata-se de um instrumento sígnico que faz a mediação da construção da escrita escolar como processo discursivo. Também, os usuários-adolescentes (e/ou crianças) de salas de bate-papo (Chats) na internet não só já dominam este instrumento quando "teclam" com seus interlocutores, como ainda criam novos instrumentos sígnicos. Além do uso de uma escrita abreviada, sincopada, parecida com a escrita escolar inicial, constroem, tácita e convencionalmente, um código discursivo escrito complexo (alfabético, semiótico, logográfico), pois usam, simultaneamente, o alfabeto tradicional, as caretinhas, os scripts, etc, para "conversar" teclando, portanto escrevendo.

A observação destes fatos me chamou a atenção para as semelhanças empíricas dos dados que vou analisar, embora os fenômenos e os processos cognitivos de aquisição e uso da escrita/escritura sejam diversos, pois ocorrem em espaços e tempos diferentes: o escolar inicial de crianças na faixa de 07 anos, aprendendo a escrever, e o ciberespacial, de adolescentes entre 12 e 17 anos, já com mestria da escrita.

Em outras palavras, de um lado, na escola, a criança usa um código abreviado, sincopado, em sua escritura inicial, para construir seu discurso, porque ainda não tem domínio do sistema de escritura, e, de outro lado, na internet, os adolescentes usam abreviações, síncopes e outros recursos (alongamentos, caixa alta, etc.) - semelhantes à forma escrita escolar inicial como recursos para a construção de um novo gênero textual escrito ("conversação escrita” - chat - na internet) com características específicas. Parece tratar-se de uma nova forma de escrita, tanto como tecnologia quanto como processo discursivo escrito, embora com marcas discursivas semelhantes às da conversação face a face oral.

A partir dessas observações e idéias, procuro descrever e analisar neste trabalho os fenômenos apontados acima, tentando explicar as possíveis semelhanças e diferenças dos dados coletados em circunstâncias e espaços enunciativos diversos, o que poderia contribuir com a compreensão dos processos cognitivos de aquisição/apropriação e uso/produção da escrita por crianças e adolescentes, destacando-se em que e como esses fenômenos e processos se aproximam ou divergem. 
Primeiramente, analiso a escritura e o processo de produção da escrita de salas de aula do ensino primário, a partir de um episódio analisado por Smolka (1993), com outro objetivo que não o meu. Em seguida, analiso a escrita de salas de bate-papo (chats) na internet. Embaso-me em Olson (1988), interligando os sistemas pictóricos, logográficos, silábicos e alfabéticos criados por diversos povos com os recursos gráficos, semióticos, topográficos, logogrâmicos etc, usados pelos internautas. Num quadro-síntese, faço um resumo das semelhanças e diferenças da escrita escolar e internética e, em seguida, um paralelo crítico entre as características da escrita e do processo de produção da escrita presentes em ambos os espaços. Finalmente, para concluir, retomo os pontos básicos descritos e analisados, apontando, teoricamente, para as semelhanças dos produtos e as diferenças dos processos cognitivos de aquisição e produção da escrita/escritura analisada.

Para desenvolver a análise, "aproprio-me" de algumas idéias de Smolka (1988 e 1993) sobre aquisição da escrita em certas circunstâncias histórico-culturais e também de algumas idéias de Olson (1998) sobre aquisição de uma língua, apropriação da escrita (e da cultura), mais como processo discursivo que como simples tecnologia. Ambos os autores têm, em comum, a perspectiva vigotskiana da psicologia cultural em que as atividades históricas e culturais transformam o sujeito e a consciência, ou seja, sua forma de funcionamento mental.

Segundo essa perspectiva, o conceito de consciência - a percepção, o pensamento e a ação - se prende ao princípio de que adquirir uma língua é o principal meio de aprender as formas de viver da cultura, uma vez que o desenvolvimento intelectual da criança deve ser visto como aquisição/ construção de sistemas representacionais e simbólicos dessa cultura. Conforme Olson (1998:89), "[...] aprender vários sistemas notacionais da cultura - isto é, o meio cultural de armazenar e passar informações em uma variedade de formas escritas e ritualizadas - desempenha um papel secundário, mas nem por isso menos significativo" (grifos meus).

A apropriação da escrita, até hoje nossa ferramenta cultural e intelectual mais reconhecida, transforma os processo e as estruturas cognitivas do sujeito, pois, segundo Vygotsky (1962 e 1978) e Luria (1946), ela nos oferece recursos não só para produzir coisas novas, mas porque, significativamente, transformou o discurso e a linguagem em objetos de reflexão e análise. Segundo Luria (1946), o escritor iniciante 
“ainda não é capaz de fazer das relações verbais e das palavras o objeto de sua consciência. Nesse período uma palavra pode ser usada mas não percebida por uma criança, e freqüentemente parece como uma janela de vidro através da qual a criança olha o mundo sem fazer da própria palavra um objeto de sua consciência e sem suspeitar que ela tem sua própria existência, suas próprias características estruturais." (citado por Downing, 1987, p. 61)

É nesse sentido que Olson (1988) defende que uma atividade secundária como a escrita se torna a atividade principal consciente, isto é, a escrita transforma o discurso em um objeto da consciência. É o que também Smolka (1993: 59) teoriza ao afirmar que quando a criança começa a escrever palavras, precisando pronunciá-las de uma outra forma, as torna objeto de sua atenção, de sua consciência. Ao aprender a ler e escrever, a criança está criando um modelo para pensar sobre a fala e a linguagem, uma atividade principal consciente, pois, segundo Olson (1998:108),

"A escrita não é uma transcrição do discurso, mas fornece um modelo conceitual para esse discurso. /.../ Os sistemas escritos, então, realmente apresentam o discurso, mas não da maneira que é convencionalmente sustentada. Longe de transcrever o discurso, os sistemas escritos criam as categorias nos termos das quais nos tornamos conscientes do discurso. /.../ É a introspecção do discurso que contribui para uma nova compreensão da mente."

\title{
2. A escrita/escritura inicial escolar: análise
}

Observemos o texto falado de um episódio de escrita inicial de uma criança de $1^{\text {a }}$. série, que foi gravado em vídeo, e pode ser assim transcrito (Smolka :1993: 50) ${ }^{1}$ :

\author{
Veee/vê \\ Era uma vez \\ $\mathrm{Um} / \mathrm{bo} / \mathrm{bo} / \mathrm{sque}$ \\ era uma vez um bosque \\ que/e/que/mo/mmos/tra/ta/ta/va/bii/ba/be/bi/bi/cho/cho/
}

\footnotetext{
1 A escola em que as crianças desta pesquisa estudam é pública e encontra-se em um bairro periférico de Campinas. O material foi recolhido nos idos de '90. Maiores informações ver obra citada.
} 
Os produtos - falado e escrito - ao final do processo são (p.55):

a) Texto final faladollido: (era) uma vez um bosque que mostrava bicho

b) Texto escrito 1 :

a $v$ u $c$

$m \quad t \quad 0$

Observemos a continuação do mesmo episódio cujo texto falado pode ser assim transcrito (p.50):

\author{
i/i/e/e/era/era/era/uma/ \\ er'uma vez/ \\ bas/bas/tan/tan/bastante/bastante/bi/ba/be/bi bi bi bi/ \\ bicho/vivo/cho/ \\ E os produtos finais - falado e escrito - são (p.55): \\ a) Texto final falado/lido: (era) uma vez bastante bicho \\ b) Texto escrito 2: $\quad a u \quad v \quad t \quad b$
}

$\mathrm{Na}$ análise que Smolka faz (op. cit.: 57-58) desse evento de letramento/ alfabetização, organizado pela professora de $1^{\text {a }}$ série, ela destaca que "a fala fluida, gravada em vídeo, permite perceber uma clara diferença entre a interpretação das marcas/signos/ letras cristalizados no papel e a apreensão da dinâmica da escritura". Ao falar o texto, a criança não diz fluentemente o que quer escrever, ou seja, o texto não sai pronto, mas a criança avança na escritura retomando e expandindo constantemente a fala na oralidade. Vocaliza porções silábicas, recorta o contínuo da fala e retoma posteriormente o texto na forma de "leitura fluente".

No início, ainda são "vogais" ou "consoantes" que representam as palavras. Expande-se a sintaxe na oralidade. Abrevia-se a representação fonológica na escrita. A criança já tem a compreensão da função da escrita, mas ainda não a usa como atividade mnemônica total. Enquanto "fala social" ou 'fala para o outro', a escrita como sistema e mecanismo ainda não pertence totalmente à criança. Mas, aos poucos, ela vai se apropriando desse novo modo "adequado" de dizer, que vai se constituindo e se consolidando como atividade discursiva.

Segundo Smolka (1993:59), esse processo de apropriação transforma o próprio sujeito, sua atividade discursiva e sua forma de funcionamento mental. O curioso, diz ela à página 60 , é que, 
"nesse processo [atividade discursiva dialógica em que a criança ocupa vários lugares: escritor/autor/leitor/narrador/protagonista do texto que "fala para si" e "tenta dizer pela escritura"], as características da fala "egocêntrica" e da escrita invertem: a fala para si é expandida, estendida e repetida, enquanto a escritura se apresenta contraída, condensada, abreviada. Expansão da sintaxe na oralidade, abreviação fonética na escrita. /.../ A função da escrita como recurso de memória parece ter sido apreendida. Mas o mecanismo e funcionamento como atividade mnemônica vai ainda se constituindo, se consolidando."

Observemos essa consolidação, a partir de outros textos, além dos dois anteriores, produzidos (Smolka, 1993) em salas de aula do curso primário, em que vai se dando esse avanço na escritura inicial, ainda cheia de signos escritos esparsos, abreviados ou aglutinados. Aos poucos, as marcas iniciais vão se transformando: a escrita truncada e ilegível das tentativas iniciais vai se tornando legível; a quantidade de omissões, abreviações e aglutinações vai se reduzindo e a escritura vai sendo marcada pelo fluxo e pela fluência da fala com suas hesitações, repetições, laços e incertezas. A materialidade das palavras ganha novas formas, vai se expandindo até a escrita, com seus mecanismos e funcionamentos, se constituir e se consolidar como atividade mnemônica e se tornar um modo "apropriado" de dizer.

Alguns recortes de textos ${ }^{2}$ produzidos por crianças de $1^{a}$ série exemplificam bem esse processo de expansão. No início os textos são bem ilegíveis e até incompreensíveis (Textos 3, 4 e 5).

Texto 3 (p.75)

Amofu

Amafeobu

Amamaifaisopam

A mamãe faso pu

(A mamãe faz pão)

Texto 4 (p.77)

opão elavanmaza

comnsa

iacapo

2 Estes textos estão em Smolka, 1993:75-92 
(o pão estava na mesa comemos e acabou)

Texto 5 (p.78)

erauavi o macaco Pego amu lie u

1 levo

paracavena

aigao ataco mlidaipeo ilatnauli

(era uma vez o macaco pegou a mulher e levou para a caverna)

(O gato atacou a mulher daí pegou ela ...?)

Aos poucos vão se aproximando da escrita convencional, embora ainda com marcas da fala, como no Texto 6 (p.86):
vinu muléque
comeno uma
Maçã i não viu
o gato ci estava
dormino in sima
domuro i a Maça
caiunaca besa

umaveis vinha

(Uma vez vinha vindo um moleque comendo uma maçã e não viu o gato que estava dormindo em cima do muro, e a maçã caiu na cabeça)

Smolka (1993:86) assim comenta este texto 6: "O texto /.../ ilustra a legibilidade, a 'quase legitimidade' da escrita que se aproxima do convencional, mas que traz, ainda, marcas da "fala" ("vinu", "comeno", "dormino"); da ambigüidade da ortografia ("ci”, "in sima”); da dúvida sobre o recorte do fuxo ("umaveis", "domuro", "caiunaca besa")."

No final do ano letivo, os textos já refletem a mestria da escrita pela criança, como tecnologia (escritura) e como processo (Texto 7: p.89-92). Este texto foi produzido a partir de uma seqüência de quadrinhos:

O leão tava passando perto da bruxa. Ele deitou querendo o rabo dele de vouta

Ele parece que estava com medo.

Porque estava com medo de que ela fazia guma mágica

E ela reagio tão rapido que feis o rabo dele desaparece. ele ficou muito triste
E ele comesou chora.

E a fadinha ficou com dó.

E a fadinha perdou

E ele não parava de chora

$\mathrm{E}$ a fadinha fez que o rabo dele de vouta 
Esses exemplos, principalmente os primeiros, parecem revelar uma escrita desconexa e incompleta, que apresenta, como já dissemos, uma tendência a condensação, abreviação, aglutinação e contração de palavras, Entretanto essa escrita inicial não pode ser analisada apenas segundo as regras lógicas, ortográficas ou gramaticais, de mera gravação de fonemas e grafemas ou cópias e repetições de idéias fragmentadas. Essa escrita revela, sim, um trabalho de escritura discursiva bastante complexo, um processo de simbolização e conceitualização de experiências de leitura e escrita construídas na interação e na interlocução sociais do espaço escolar.

\section{A escrita/escritura em sala de bate-papo: características e análise}

Estamos agora em outro espaço enunciativo - o ciberespacial - o que explicaria, em contrapartida, a nota quatro que uma professora deu à redação de um aluno, uma vez que a escola, geralmente, valoriza o nível formal da linguagem, numa atitude, muitas vezes preconceituosa ${ }^{3}$. Assim a professora justifica a nota baixa dada: "Isto não é internet, abreviações e desenhinhos não valem aqui" -, embora a influência do estilo web do "falar-escrito" (teclando) seja cada vez mais comum na escritura cotidiana, como podemos ver no bilhete escrito por esse mesmo sujeito e deixado para a mãe na porta da geladeira:

M@E, VOU NO NÍVER DA PAULA, A GATA D+ Q T FALEI; N

FALA DA FESTA PRA BETE; VC SABE PQ... HEHEHE.... QQ

COISA TÔ NO CEL, BLZ?

BJ

F

Esse novo espaço enunciativo de comunicação eletrônica permite uma escrita, uma leitura e uma difusão que não são limitadas geograficamente e seus usuários, ao utilizarem certos dispositivos, como os chats, Icq, Irc, MSN, Skype, e mesmo o correio eletrônico (e.mail), materializam um novo código discursivo a partir de recursos semióticos ou de artefatos eletrônicos que aí existem. Eles alargam e enriquecem sistemas lingüísticos e discursi-

V. COSTA, S. R. \& PEREIRA, A. P. M. S., 2002 e 2004. 
vos já existentes, movidos por novas motivações enunciativas desta nova esfera social cuja interação é virtual. Para tal, os internautas usam um novo código discursivo e cultural, espontaneamente construído, que se caracteriza como um conjunto de recursos icônicos, semióticos, logográficos, tipográficos e telemáticos.

Esses recursos, já existentes (sinais de pontuação, abreviações, elementos gráficos, maiúsculas, etc), são reutilizados pelos usuários para o desenvolvimento do falar-escrito ou da escrita-oralizada, de caráter híbrido, muito próprio dos chats (bate-papo) da internet, uma interação bastante informal. Segundo Anis (2000) trata-se e uma norma scripto-conversacional (nova grafia) do espaço eletrônico, a qual visa facilitar a redação de mensagens e regular as trocas de interação verbal e social na internet. Novas motivações enunciativas (relações de amizade, atitudes lúdicas do falarescrever, procura de expressividade, afetividade ou emotividade...) desta nova esfera de vida social criam uma nova variedade de linguagem, específica desse novo modo de comunicação.

Os usuários da internet estariam mesclando os três sistemas básicos de escritura, histórica e culturalmente construídos pela humanidade (o sistema ideográfico - pictogramas e ideogramas; o sistema silábico e o sistema alfabético), e também novos recursos eletrônicos e midiáticos mais recentes. Em outras palavras, ontogeneticamente, os adolescentes, freqüentadores das salas de bate-papo, estariam mesclando, não necessariamente nesta ordem, a escrita de desenhos que representaria as idéias diretamente; os sistemas escritos baseados em palavras; os sistemas silábicos não vocalizados ou sistemas consonantais ${ }^{4}$ e o sistema alfabético, em que as diferenças de vogais fazem os controles lexicais's (em português, tudo é diferente de todo; em inglês, bad é diferente de bed), inventando um novo "sistema escrito" ou um novo "código discursivo".

\footnotetext{
4 "Porém, as línguas semíticas têm a propriedade curiosa de carregar identidades lexicais da língua no que consideramos consoantes; o que consideramos vogais, era usado somente para flexões. Para ilustrar, o grupo de $/ \mathrm{k} / \mathrm{h} / \mathrm{t} / \mathrm{e} / \mathrm{b} /$ vocalizados de alguma maneira de modos diferentes exprimem o lexema básico "escrita" com diferenças vocálicas marcando o sujeito, o tempo e o aspecto: katab "ele escreveu", katabi "eu escrevi", katebu "eles escreveram" /.../. Tudo pode ser escrito simplesmente ktb". (Olson, 1988:101)

5 A transição "final" da escrita consonantal para a alfabética ocorreu, unicamente na história, quando a escrita foi adaptada por uma língua não-semítica, o grego." (Olson, 1988:102)
} 
Inventar um sistema escrito é, em parte, descobrir algo sobre o discurso. É o que esses usuários estariam fazendo validando as hipóteses de Harris (1986), Gaur (1984/1987) e Olson (1988), segundo a qual os sistemas escritos foram criados não para representar o discurso, mas para comunicar informação, explicar, narrar e não apenas nomear. Ou na concepção de Olson (1988:93), segundo a qual "os sistemas escritos fornecem os conceitos e as categorias para refletir sobre a estrutura da linguagem falada, e não o inverso".

Em outras palavras, em vez de tentar captar o conhecimento existente da sintaxe, a escrita forneceu um modelo para o discurso, ou seja, a história da escrita é essencialmente a modelação teórica da forma verbal. Os emblemas ou desenhos, a partir do momento em que adquiriram uma sintaxe e tornaram-se um sistema escrito, podem ser vistos como uma frase enunciativa e não uma mera lista. Quando os adolescentes, em salas de batepapo, criam um novo código discursivo e cultural, a partir de novas motivações enunciativas, para o desenvolvimento do falar-escrito, eles estão criando uma nova escrita/escritura que também fornece um novo modelo para o discurso. A partir do momento que os recursos gráficos, logográficos, icônicos, tipográficos, telemáticos já existentes são reutilizados, combinando e recombinando sintaticamente, criam uma nova leitura, ressignificando o discurso, e se tornam um novo "sistema escrito" de um novo espaço enunciativo - o ciberespacial.

Alguns fragmentos de textos recortados de produtos escritos em salas de bate-papo (chats) podem exemplificar o que dissemos ${ }^{6}$. À medida que vamos resumindo as características da escrita e escritura ${ }^{7}$ desse espaço, vamos também analisando os fragmentos que nos servem de exemplo.

Vejamos como o próprio usuário caracteriza a escrita/escritura dos chats. Além de ser informal e coloquial, fugindo do uso padrão, falado ou escrito, ela é bastante

6 O exemplos aqui citados encontram-se nos artefatos da pesquisa de FREITAS, M.T.A \& COSTA, S.R. Construção/produção da escrita na Internet e na escola: um enfoque sócio-histórico. Projeto CNPQ/1999-2000-2001. Os sujeitos da pesquisa são pré-adolescentes e adolescentes (faixa etária entre 11-17 anos e classe social variada) que estudam em colégios públicos e particulares da cidade de Juiz de Fora, MG.

7 Refiro-me à escrita como processo e à escritura como artefato técnico, ligado à história das técnicas industriais. 
(i) abreviada, sincopada, contraída, às vezes, sem marcas de fronteiras entre as palavras como na escrita escolar inicial:

Session Star: Sun abr 02 11:43:13 2000

1. $<$ Wally $>$ vc entra no sábado e no domingo?

$<$ Wally $>$ sempre com esse nick?

$<$ Felipe-15> é

$<$ Felipe-15> e vc?

$<$ Felipe-15 $>$ abreviaçam geral

$<$ Wally $>$ legal... além do mirc o que mais vc faz na net?

$<$ Felipe-15 $>$ icq

$<$ Felipe-15 $>$ chat terra

$<$ Felipe-15 $>$ terra chat

$<$ Wally $>$ vc não usa o til, pq?

$<$ Felipe-15 $>$ pq demora

$<$ Felipe-15 $>$ é chato

$<$ Felipe-15 $>$ naum tem necessidad

$<$ Wally $>$ acho isso muito legal...

$<$ Felipe-15 $>$ é bom q pde escreve tudu erradu

$<$ Felipe-15> da manera q c fala

2 E o seu? Oq tapensando?

3. Colé pagodeira? (qual é pagodeira?)

4. poetatiraecenome (poeta tira esse nome, o nickame poeta)

(ii) a abreviação fonética, quando usada, a torna um sistema escrito não vocalizado ou consonântico ${ }^{8}$.

$q$ tc? Ninguém quer tc comigo? = (quer teclar? Ninguém quer teclar comigo?)

De onde $v c t c ?$ ? (De onde você tecla?)

To tc agora! = (Tô teclando agora!)

Bjs pra $v c t b:)=($ Beijos pra você também: $))$

(iii) Entonacional: esta característica é expressa por sinais de pontuação em excesso, principalmente interrogações e exclamações; letras maiúsculas (caixa alta), alongamentos..., muitas vezes, usados simultaneamente, como nos exemplos abaixo:

Session Start: Sat Apr 08 14:20:51 2000

Session Ident: StarFox (star.fox@catar.powerline.com.br)

1. < StarFox > Já ??????????????

8 Parece com o comportamento lingüístico que destacamos na nota de rodapé 4 sobre as línguas semíticas. 
2. StarFox $>\mathrm{Pq}$ ??

$<$ Ana-Flavia $>$ mt trabalhos

$<$ StarFox $>$ hummmm ..

$<$ StarFox $>$ Meus pêsames !!

3. < StarFox > ME DÁ UMA EXPLICAÇÃO PRA ISSO OWWWWWWWW !!!!!!

$<$ StarFox $>$ pq tá rindo ?

$<$ Ana-Flavia $>$ perai ... vc nao recebeu?

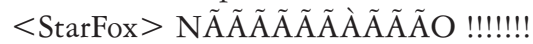

4. $<$ StarFox $>$ Ainda ñ chegou ?????

$<$ Ana-Flavia $>$ mandei um dcc pra vc

$<$ Ana-Flavia $>$ vc nao aceitou

$<$ StarFox $>$ CLARO Q SIM !!!!!!!!!!!!!!!

$<$ StarFox $>$ CLARO Q SIM !!!!!!!!!!!!!!!

5. <Ana-Flavia $>$ la vai < 4 tarFox $>$ HEIN ??

$<$ StarFox $>$ PQ ISSO ?? < <tarFox $>$ HEIN ??

$<$ StarFox $>$ PQ ISSO ?? < <tarFox $>$ HEIN ??

$<$ StarFox $>$ PQ ISSO ?? $\quad<$ StarFox $>$ FALA ALGUMA COISA OW !!!

(iv) Recursos icônicos "paralingüisticos": caracteretas/caretinhas (emoticons), topogramas, scripts, risadas...

1. $<$ StarFox $>$ Pena q ñ consigo ver ele !!

$<$ StarFox $>:(=$ (triste $)$

$<$ Ana-Flavia $>$ ja foi la?

$<$ StarFox $>$ Sim !!

$<$ StarFox $>:((((=$ (muito triste)

$<$ StarFox $>$ ñ ten nada!!

$<$ StarFox $>: \sim(\quad=$ (infeliz)

$<$ Ana-Flavia $>$ hehehe $=$ (risos)

$<$ StarFox > ME DÁ UMA EXPLICAÇÃO PRA ISSO OWWWWWWWW !!!!!!

$=$ (gargalhando)

$<$ StarFox $>$ pq tá rindo?

$<$ Ana-Flavia $>$ perai ... vc nao recebeu?

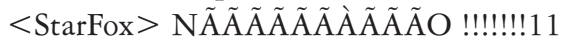

$<$ StarFox $>$ : ( $\sim \sim \sim \sim \sim \sim \sim \sim \sim=$ (muito, muito infeliz)

$<$ Ana-Flavia $>$ to tentando mandar

$<$ StarFox $>:()))))))$ ) $=($ muito infeliz)

$<$ StarFox $>$ Aki ...

$<$ StarFox $>$ Vou ter q sair ...

$<$ StarFox $>$ : (()((()((()( $=$ (muito, muito triste)

$<$ StarFox $>+$ tarde a gente se fala tá? 


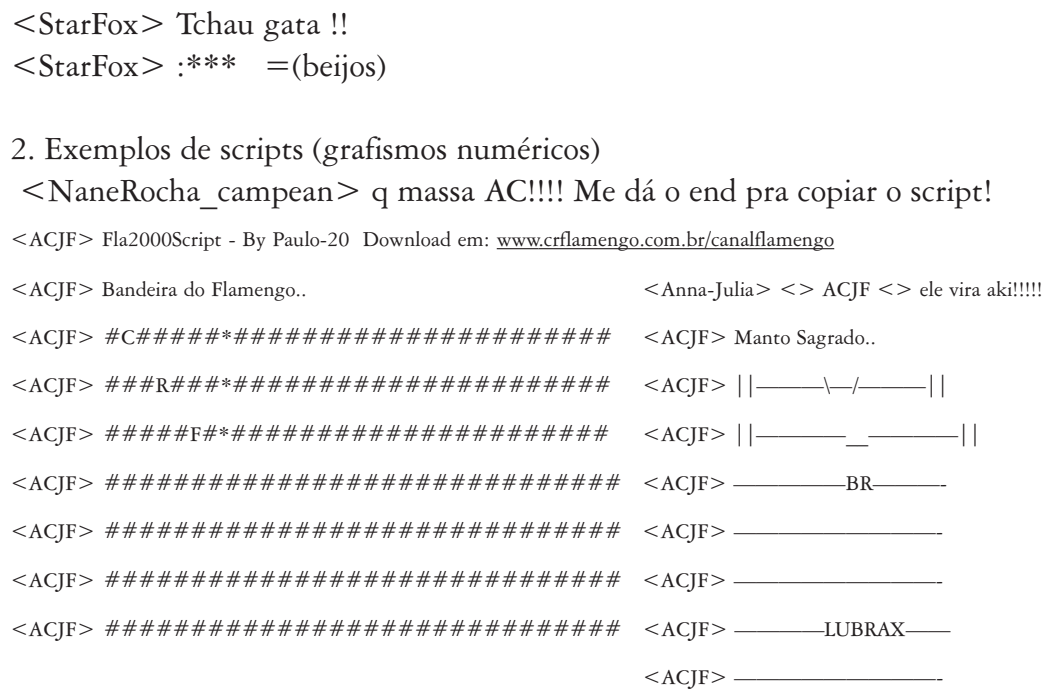

Todas essas características constituem um novo código (sistema de escrita e de escritura) discursivo criado pelos internautas. Ontogenicamente, os usuários dos chats sócio-construíram, sócio-convencionaram, reinventaram, ressignificaram na práxis formas de escrita e escritura híbridas escripturais [desenhos, scripts], logográficas, topogrâmicas, alfabéticas...), com uma nova sintaxe e novo ritmo "conversacional", com novas formatações lingüístico-rituais, com novos parâmetros espaço-tipográficos.

\section{Em síntese}

Esse novo código é, ao mesmo tempo, alfabético, consonântico, logográfico, topogrâmico, semiótico, telemático, com abreviações ou síncopes e outros recursos (alongamentos, caixa alta, sem delimitações de fronteiras entre as palavras, etc.) - o que torna os produtos das salas de bate-papo, muitas vezes, bem semelhantes aos textos escolares iniciais.

Observemos o quadro abaixo, onde podemos detectar um conjunto de características comuns e semelhantes entre as duas escritas/escrituras, a escolar inicial e a internética: 


\begin{tabular}{|c|c|}
\hline Escrita/escritura inicial escolar & Escrita/escritura em sala de bate-papo \\
\hline $\begin{array}{l}\text { Abreviada, sincopada, contraída } \\
\qquad \text { Elavanmaza } \\
\text { (estava na mesa) } \\
\text { comnsa } \\
\text { (comemos) }\end{array}$ & $\begin{array}{l}\text { Abreviada, sincopada, contraída } \\
\text { Colé? (qual é?) } \\
\text { Eu vosair (vou sair) } \\
\text { Pq esse nick? (nickname) }\end{array}$ \\
\hline $\begin{array}{l}\text { Abreviação fonética: predomínio de } \\
\text { consoantes } \\
\text { u } \quad \mathrm{v} \quad \mathrm{t} \quad \mathrm{b} \\
\text { uma vez bastante bicho }\end{array}$ & $\begin{array}{l}\text { Abreviação fonética: predomínio de consoantes } \\
q t c ?=(\text { quer teclar? } \\
\text { De onde } v c t c ?=(\text { De onde você tecla } ?) \\
\text { Bjs pra } v c t b:)=(\text { Beijos pra você também: }))\end{array}$ \\
\hline $\begin{array}{l}\text { Sem delimitação de fronteiras entre as } \\
\text { palavras } \\
\text { Amamaifaisopam } \\
\text { (a mamãe faz o pão) } \\
\text { Iacapo } \\
\text { (e acabou) }\end{array}$ & $\begin{array}{l}\text { Sem delimitação de fronteiras entre as palavras } \\
\text { Oq tapensando? (O que tá pensando?) } \\
\text { Poetatiraecenome (poeta tira esse nome) }\end{array}$ \\
\hline $\begin{array}{l}\text { Vai se expandindo/consolidando como } \\
\text { atividade mnemônica } \\
\ldots \\
\text { Porque estava com medo de que ela fazia } \\
\text { guma mágica } \\
\text { E ela reagio tão rápido que feis o rabo } \\
\text { dele desaparece. } \\
\ldots\end{array}$ & $\begin{array}{l}\text { Em forma contraída/abreviada, ressignifica o sistema de } \\
\text { escrita, já adquirido, como atividade mnemônica } \\
q t c ? \text { (quer teclar?) } \\
\text { Ninguém quer } t c \text { comigo? = (Ninguém quer teclar } \\
\text { comigo?) } \\
\text { De onde } v c t c ?=\text { (De onde você tecla?) } \\
\qquad \text { To tc agora! = (Tô teclando agora!) }\end{array}$ \\
\hline $\begin{array}{l}\text { Apropriação discursiva da escrita } \\
\text { alfabética como recuperação de } \\
\text { informações culturais } \\
\text { Texto } 5 \text { - p6 } \\
\text { O leão tava passando perto da bruxa. } \\
\text { Ele parece que estava com medo. } \\
\text { Porque estava com medo de que ela fazia } \\
\text { guma mágica } \\
\text { E ela reagio tão rápido que feis o rabo } \\
\text { dele desaparece. } \\
\text { ele ficou muito triste }\end{array}$ & 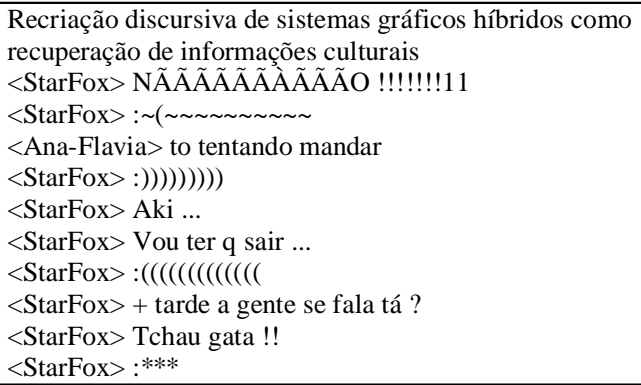 \\
\hline
\end{tabular}

Embora esse quadro nos apresente características comuns e semelhantes entre as escritas quanto ao produto e ao processo, temos algumas diferenças nos fenômenos e no processo de aquisição/contrução e de uso/ produção da escrita/escritura que marcam as ações executadas pelas crianças na escola e pelos adolescentes nas salas de bate-papo, como dissemos na introdução?

\footnotetext{
9 Estamos nos referindo às similaridades e/ou diferenças da escrita como produto e não aos fenômenos e processos cognitivos de apropriação e/ou produção da escrita que são diferentes no que se refere à maturação biológica e cultural dos sujeitos em análise. Ver Conclusão deste artigo.
} 
Podemos assim resumir essas diferenças:

(i) diferentemente das crianças que vão para a escola aprender a escrever e se apropriar da escrita como sistema simbólico, os usuários-adolescentes de salas de bate-papo (Chats) na internet não só já dominam este instrumento quando "teclam" com seus interlocutores, como também criam novos instrumentos sígni$\cos$;

(ii) ao contrário da escrita escolar inicial das crianças que ainda se apresenta abreviada, contraída, na adolescência os usuários de chats já têm sua escrita consolidada, expandida, ou seja, eles já têm a mestria da escrita;

(iii) na escola, a fala-leitura amplia o que está escrito, nos chats da internet, a escrita em que se conversa é abreviada;

(iv) na internet, tem-se um novo espaço - o ciberespacial -, em que a velocidade do suporte, aliada à velocidade da fala/conversaescrita (chats) - um novo gênero textual e discursivo - exige um novo estilo de escrever, em que são usados múltiplos recursos semióticos, já existentes em nossa cultura, que tornam a escrita mais rápida, semelhante ao que acontece na conversação face a face;

(v) na escola, as marcas da oralidade vão desaparecendo, à medida que as crianças se apropriam da escrita formal;

(vi) nos chats da internet, ao contrário, as marcas da oralidade são muito fortes e presentes nos textos dos papeadores (escreve-se quase como se fala);

(vii) na escola, as crianças saem do uso coloquial e informal da linguagem oral para o uso de uma linguagem escrita padrão;

(viii) nos chats da internet, os papeadores usam uma linguagem escrita bastante coloquial e informal.

\section{Conclusão}

Procurei, neste trabalho, dar uma possível interpretação aos fenômenos e processos de aquisição/apropriação e uso/produção da escrita inicial 
escolar ( 1 a . Série) e da escrita "criada" no chat da internet por adolescentes, descrevendo e analisando suas similaridades e diferenças, sob uma perspectiva enunciativo-discursiva. Nesta perspectiva, embora se tenha espaço e tempo diferentes (escolar e ciberespacial), discurso e linguagem são objetos de reflexão e análise por parte das crianças na escola e por parte dos adolescentes na internet (chat), ou seja, a escrita transforma o discurso dos sujeitos em objeto da atenção e da consciência. Nesse sentido, tanto a criança, na fase inicial da escrita escolar, quanto o adolescente no chat da internet, criam um novo modelo para pensar sobre a fala e a linguagem como atividade consciente numa perspectiva em que a escrita não é uma mera transcrição do discurso. Ou seja, tanto o escritor iniciante, na escola, quanto o adolescente, no ciberespaço, se apropriam de uma ferramenta cultural e intelectual que lhes dá recursos para produzir coisas novas, isto é, criar novos sistemas representativos e simbólicos da cultura em que estão inseridos, como processo discursivo e não apenas como simples tecnologia.

Contudo, a criança, escritor iniciante na escola, ainda não é totalmente capaz de fazer das palavras e das relações verbais o objeto de sua consciência. Ela tem a compreensão de cada função da escrita, mas ainda não a usa eficazmente como atividade mnemônica, embora ocupe vários lugares na interação verbal (escritor/ator/leitor) e sua escrita, então, se apresenta abreviada/sincopada/truncada/aglutinada. Já o adolescente do chat da internet usa eficazmente a escrita e a escritura como atividade mnemônica, inclusive, construindo um novo código discursivo abreviado/sincopado/truncado/ aglutinado, próprio de um novo gênero emergente na internet - $\mathrm{o}$ chat ou bate-papo informal, o que torna ambos os produtos semelhantes. Entretanto os processos cognitivos de apropriação e/ou produção da escrita, são diferentes no que se refere à maturação biológica e cultural dos sujeitos em análise, já que se dão em tempos e espaços enunciativos diferentes (escola e chats informais da internet), em que crianças e adolescentes usam ferramentas, suportes e dispositivos técnicos diversos para ler e escrever.

Recebido em maio de 2004 Aprovado em julho de 2005

E-mail: costasero@uol.com.br

\section{Referências Bibliográficas}

Anis, J. 2000. Modifications dans les pratiques d'écriture. Le Français Aujourd'bui, n. 129, 3, Paris: AFEF: 59-69. 
Costa, S. R. \& A. P. M. S. Pereira. 2002. Conceitos e preconceitos sobre a escrita na internet e na escola. Presença Pedagógica, v.8, n.48: 35-51, nov./dez. Belo Horizonte: Dimensão. (ISSN 1413-1862).

. 2004. O teclar e o escrever: conceitos e preconceitos lingüísticos, culturais e sociais. Estudos em Avaliação Educacional, no. 29: 87-109, jan-jun/2004, São Paulo, Fundação Carlos Chagas. (ISSN 0103-6831). Downing, J. 1987. Comparative perspectives on world literacy. D. Wagner (Ed.) The future of literacy in a changing world. Oxford: Pergamon Press: 25-47.

Freitas, M. T. A. \& S. R Costa. 2001. Construção/produção da escrita na Internet e na escola: um enfoque sócio-histórico. Projeto CNPQ/1999-20002001. Cópia eletrônica.

Gaur, A. 1984. A bistory of writing. London: British Library, 1987.

HARRIS, R. 1986. The origin of writing. London: Duckworth.

Olson, D. R. 1988. A escrita e a mente. In Wertsch, Rio \& Alvarez (Orgs.) Estudos socioculturais da mente. Porto Alegre: Artmed: 89-111.

SmolkA, A. L. B. 1988. A criança na fase inicial da escrita: a alfabetização como processo discursivo. São Paulo: Cortez, 1993.

. 1993. A dinâmica discursiva no ato de escrever: relações oralidadeescritura. In SMOLKa \& GóEs (orgs.) A linguagem e o outro no espaço escolar. Campinas: Papirus: 75-92.

Vygostky, L. 1962. Thought and language. Cambridge, MA: MIT Press. . 1978. M. Cole, V. John-Steiner, S. Scribner, \& E. Souberman (Eds) Mind in society: The development of higher psychological processes. Cambridge, MA: Harvard University Press. 